\title{
Effect of Deep Friction Massage with Taping Technique on Strength, Pain, Function and Wrist Extensor Muscle Activity in Patient with Tennis Elbow
}

\author{
Jeong-Hoon Lee, PT, MS ${ }^{1}$; Jae-Seop Oh, PT, Ph.D ${ }^{2}$; Moon-Hwan Kim, PT, Ph.D ${ }^{3}$ \\ ${ }^{1}$ Department of Rehabilitation Science, The Graduate School, Inje University, Gimhae, South Korea \\ ${ }^{2}$ Department of Physical Therapy, College of Biomedical Science and Engineering, Inje University, Gimhae, South Korea \\ ${ }^{3}$ Department of Rehabilitation Medicine, Wonju Severance Christian Hospital, Wonju, South Korea
}

Background Lateral epicondylitis, generally referred to as tennis elbow, is a common condition JMST of the forearm. Treatment typically includes specialized manual therapy, including deep friction massage (DFM), taping, and Mill's manipulation.

Purpose The aim of this study was to evaluate changes in pain, function, strength, and muscle activity following taping with DFM.

Study design Randomized controlled trial

Methods We recruited 30 patients with tennis elbow and equally divided into two groups using randomization (Taping group versus taping and DFM group). Pre- and post-intervention measures included a visual analog scale (VAS) pain scores, the Patient-rated Tennis Elbow Evaluation (PRTEE) questionnaire, pain-free grip strength (PFGS), wrist extensor strength (WES), and wrist extensor electromyography (EMG). DFM and diamond taping were applied as the study intervention. The differences between pre- and post-intervention outcome measures were analyzed using two-way repeated-measures analysis of variance.

Results A significant time-by-group interaction was observed for the VAS, PRTEE scores, PFGS, WES, and EMG. A post hoc paired $t$-test showed that pain, function, and strength improved significantly post-intervention in the group treated with taping and DFM. The VAS and PRTEE scores significantly decreased, and PFGS, WES, and EMG significantly increased in both groups post-intervention.

Conclusions Our findings demonstrated that taping with DFM can be an effective strategy for decreasing pain, improving function, and increasing strength and muscle activation in patients with lateral epicondylitis.

2020; 4(2): 76-83

Published Online Dec 31, 2020 pISSN 2635-8573 eISSN 2635-8581

Article History Received 8 Oct 2020 Revised 18 Oct 2020 (1st)

Revised 24 Nov 2020 (2nd)

Accepted 26 Nov 2020

\section{CONTACT}

agafimu@hanmail.net

Moon-Hwan Kim,

Department of

Rehabilitation Medicine

Wonju Severance

Christian Hospital,

Wonju, South Korea

This is an Open-Access article distributed under the terms of the Creative Commons Attribution Non-Commercial License (http///creativecommons. org/licenses/by-nc/4 0) which permits permits unrestricted non-comercial use, distribution, and reproduction in any mewin, provided the ongina work is properly cited.

Key words Deep friction massage; Lateral epicondylitis; Strength; Taping; Tennis elbow.

\section{INTRODUCTION}

Tennis elbow is also called lateral epicondylitis, which is a syndrome in which joint ridges start nodules above the elbow joint (medial and lateral epicondyle start nodules), ${ }^{1,2,3}$ wrist bending or flexion causes pain or local tenderness at the point where muscles are started. ${ }^{3,4,5}$ It is one of the most common causes of joint pain. Excessive exercise using arms such as tennis, people who use a lot of work arms, excessively quick simple movements, and repetitive knitting cont- raction shortens the ulnar extensor muscle at the start point of lateral epicondyle, causing inflammation occurs. ${ }^{6-10}$ Treatment methods include corticosteroid injections, which have a short-term effect, and time-consuming, ${ }^{11,12}$ but noninvasive physical and specific frequency therapies, including deep friction massage (DFM), taping, Mill's manipulation, and wrist movement, etc. These taping and DFM are therapeutically accessible and are widely used in clinical practice. ${ }^{13-16}$

DFM is known to affect muscle tissue in the vertical 
direction of fibers, ${ }^{17}$ mechanically cause hyperemia, rearrange collagen in normal soft tissue, and reduce pain through "barrier regulation theory", and reduce inflammation, It has been reported that it destroys or prevents abnormal fiber adhesions, reduces stress, remodels collagen, and improves the quality of wound tissue. ${ }^{18,19}$ In a previous study, it was reported that when DFM was applied to tennis elbow patients, it improved the pain reduction function and increased the pain-free grip strength, hand grip strength, and hand grip endurance. ${ }^{20}$ However, no studies have examined the increase in wrist extensor muscle strength when DFM is applied. And there were studies applying DFM where the extension angle and function of the wrist were not significantly improved or increased with other treatments.

Taping regulates the passive length of muscles, increasing muscle strength, improving muscle function and suppressing $\alpha$-motorneurone, reducing pain, fixing body parts and fixing imbalances rather than imbalanced parts. ${ }^{11,21-23}$ Widely used in motor rehabilitation programs to facilitate therapy with therapeutic methods that display tension higher to improve muscle strength and provide proprioceptive feedback to learn motor memory and restore functional movement patterns used. ${ }^{23}$ The elbow taping technique was used to treat tennis elbows, and there was a study that reduced pain, improved function, and increased pain-free grip strength by $24 \%$, increasing wrist extensor muscle strength by $11.6 \mathrm{~N} .{ }^{22}$ However, no studies evaluated the patient's hand grip endurance after applying taping to tennis elbow patients. In addition, previous study in which taping, exercise, and treatment were applied to people with Patellofemoral pain to measure muscle activity, muscle activity was not significantly increased compared to other exercise and treatment. ${ }^{17}$ There was no significant increase over other exercises and treatments. One treatment intervention can also increase pain, function, and muscle strength in tennis elbow patients, but not sure about wrist extensor muscle strength, function, muscle activity and hand grip endurance.

The results of these inconsistent studies are those that were shown to apply only one treatment, and when taping or DFM applied the other treatments together, applied only one treatment. There were studies that showed a better effect than the ones. The results of such studies are considered to be better when the two treatments are applied together.

Therefore, the purpose of our study was to investigate the effectiveness of taping and DFM on the pain, function, strength and EMG when comparing the effects of taping for patients with tennis elbow. Our hypothesis was that compared to taping alone, taping and DFM together were more effective in improvements of pain, function, muscle strength, muscle activity in patients with tennis elbow.

\section{METHODS}

\section{Subjects}

Thirty tennis elbow patients (10 males, 20 females, age $36.97 \pm 14.91$ years, height $166.50 \pm 7.89 \mathrm{~cm}$, weight $59.27 \pm$ $11.88 \mathrm{~kg}$ ) were recruited in the study. Patients were recruited to the physiotherapy unit through public advertisements and referrals to the exercise center. All subjects were diagnosed with tennis lateral epicondylitis by a physician prior to treatment and all treatments were applied to the subject's predominant hand. The patient had symptoms from 6 months to 5 years ago. All subjects complained of tenderness in the Extensor carpi radialis brevis tendon. The inclusion criteria were patients who were diagnosed with a tennis elbow by a specialist and felt pain when performing a cozen test or maudsley test. ${ }^{24}$ Bleeding, skin disease, external perchloric surgery on the elbow, carpal tunnel syndrome, cervical spinal nerve injury, upper limb fractures, tape allergy, and treatment with steroid injections within the last 6 months, physiotherapeutic treatment of the upper extremity with neurological abnormalities or orthopedic disorders of the upper extremity and who recently received other treatments were excluded. ${ }^{24}$ The 30 subjects were randomly divided into 15 taping groups and 15 taping and DFM groups. This study was conducted after passing the deliberation of the Institutional Bioethics Committee of Inje University (INJE2016-11-016-002).

\section{Experimental equipment and tools}

\section{Visual analogue scale (VAS)}

Patient pain was measured using VAS. The VAS has indicated the pain felt by the patient on a table made up of $10 \mathrm{~cm}$ lines. When there is almost no pain, 0 is displayed, and pain that cannot be tolerated is displayed as 10 . VAS has been validated and validated through previous studies to measure the degree of pain commonly felt on the elbow. ${ }^{25}$

\section{Patient-rated tennis elbow evaluation (PRTEE)}

Patient function was measured using the Patient-rated Tennis Elbow Evaluation (PRTEE). PRTEE consists of 15 items, 5 items of pain, 10 items of elbow function, 0-50 points for pain area, 0 to 100 points for elbow function area, and the total score of the $0-100$ points. function area score was divided into 2 and the high score was set to 50 so that the total score of the pain evaluation area and the functional evaluation item could be 100 points. If you do not respond to the evaluation items, it is assumed that you have not 
executed at all. ${ }^{26}$

\section{Pain-free grip strength}

Pain-free grip strength (PFGS) was measured using a Jamar hydraulic hand dynamometer (PC 5030JI, Preston Corporation, USA). The patient was comfortably seated in a chair, the elbow was bent 90 degrees, the wrist was measured in a neutral position, the other hand was comfortably placed, and the subject's upper arm was attached to the torso. I took a break after grasping the dynamometer so strongly that I did not feel pain for 5 seconds. The PFGS was measured three times with a patient's uncomfortable grip, and the average of the measurements was used for data analysis. In previous studies, the reliability of the hand dynamometer was $0.973 .{ }^{21}$

\section{Wrist extension strength}

A patient's wrist extension strength (WES) was measured using a Hand-held dynamometer (POWER TRACK II, JTech Medical, Salt I lake City UT). Measuring with the patient sitting directly on the chair, the elbow of the hand was bent 90 degrees and placed comfortably on the table. Place the other hand comfortably on your lap, put your wrist out of the corner of the table, and put your wrist in a neutral position. The fingers are bent so as to apply force to the metacarpophalangeal joint of the third finger. The value is measured so that the patient does not feel uncomfortable. It measured 3 times and analyzed the average value. In previous studies, the Hand-held dynamometer showed a reliability of $0.80 .^{22}$

\section{Electromyography}

Wrist extensor muscle activity of patients was measured using surface EMG (2EM, 4D-MT, Relive, Gimhae, Korea. Notch filter $60 \mathrm{~Hz}$, bandpass $20-450 \mathrm{~Hz}$, sampling, $1000 \mathrm{~Hz}$ ). Before applying the electrodes, they were cleaned with alcohol cotton and shaved to reduce skin resistance, then rubbed with soft sandpaper. The electrodes were attached to the extensor digitorum, extensor carpi radialis brevis, and flexor carpi radialis at intervals of $2 \mathrm{~cm}$. For Surface EMG measurements, the patient was immediately seated in a chair with feet in contact with the floor, the shoulders collected, and placed in a neutral rotational position. The patient flex elbow 90 degrees and placed lower arm in a neutral position. The unmeasured arm was placed comfortably on the knee. The wrist should be extension between 0 and 30 degrees, the resistance should be given to give the maximum force, the EMG should be measured for 5 seconds, and the value for the middle 3 seconds should be the value of maximum voluntary isomeric contraction (MVIC). Used as a value. After measuring three times, the average value was used as a baseline, and the wrist was moved to the temple for 5 seconds without discomfort, and the middle 3 seconds was generalized. $^{24}$

\section{Procedure}

Subjects in the two groups measured all pre-intervention VAS and PRTEE, followed by wrist extensor electromyography, pain-free grip strength and wrist extension strength.

\section{1) Taping group}

The group to which taping was applied taping to the wrist extensor site of the subject's dominant hand. A non-stretching $3.8 \mathrm{~cm}$ thick tape was cut into $8-10 \mathrm{~cm}$ and applied in the shape of a diamond in the direction close to the far side of the four skins. At this time, it was attached so that the texture of the skin looked like orange peel. After attaching the tape, VAS, PRTEE, wrist extensor EMG, pain-free grip strength and wrist extension strength were measured.

\section{2) Taping and DFM group}

For groups with taping and DFM applied together, it is difficult to apply taping first and then DFM, so after applying DFM and Mill's manipulation for the first 15 minutes, apply taping as with taping groups. After tape application, VAS, PRTEE, wrist extensor EMG, pain-free grip strength, wrist extension strength were measured.

\section{Statistical analysis}

The average and standard deviation of VAS, PRTEE, wrist extensor EMG, pain-free grip strength, wrist extension strength are analyzed using SPSS program (ver. 22.0 for Windows; SPSS Inc., Chicago, IL, USA), and Two-way repeated-measures analysis of variance (ANOVA) was used to compare the VAS, PRTEE, wrist extensor EMG, pain-free grip strength, wrist extension strength within and between groups. The $p$ value was set to 0.05 or less.

\section{RESULTS}

The data in this study show positive changes in VAS, PRTEE, wrist extensor EMG, Pain-free grip strength, and wrist extension strength in Tennis elbow patients with DFM and taping compared pre and post intervention. VAS appeared in the taping and DFM groups at $5.3 \pm 1.25$ and $1.4 \pm 0.63$ with $p<0.001$, and in the taping group as $5.2 \pm 0.96$ and $1.67 \pm 0.50$ with $p$ value of 0.010 . There was no significant difference between the groups. PRTEE was $33.43 \pm 8.03$ 
in the taping and DFM group, $12.3 \pm 4.17$ and $p$ value was 0.001 , and PRTEE was $31.63 \pm 7.50$ and $14.83 \pm 5.60$ was 0.001 in $p$ value. The $p$ value was 0.012 and the taping and DFM groups were more significant than the taping group. Pain-free grip strength was $26.16 \pm 10.70$ at $30.24 \pm 10.95$ at $p$ $<0.001$ for taping and DFM group, and 21.87 \pm 7.47 at $24.50 \pm 7.70$ at $p<0.001$ for taping group. The difference between groups was $p<0.001$, and the taping and DFM groups were more significant than the taping group. The wrist extension strength was $83.94 \pm 24.97,101.88 \pm 27.59$ and $p<0.001$ at taping and DFM group, and $93.33 \pm 26.80$ and $p<0.001$ at $85.19 \pm 25.91$ in taping group. The difference between groups was $p<0.001$, and the taping and DFM groups were more significant than the taping group. In the wrist extensor EMG, the taping with DFM group was $61.25 \pm 6.98$, the $p$ value was 0.010 at $75.25 \pm 19.03$, and the taping group was $71.47 \pm 8.19$, the $p$ value was $76.77 \pm 7.57$, and the $p$ value was 0.017 . It was observed that there was no significant difference between the groups. (Tables 1,2).

\section{DISCUSSION}

In this study, when taping and DFM were applied to tennis elbow patients, taping group and taping and DFM were applied by measuring VAS, PRTEE, pain-free grip strength, wrist extension strength, and wrist extensor EMG of the patients. We compared the differences between groups pre and post intervention and between groups.

In the study, the effect on pain was significantly lower in pre-intermediation and post-intervention VAS in both the taped group and both taped and DFM groups. However, the interaction between pre-intervention and post-intervention did not show a significant value in the group where VAS did not show a significant difference between the two groups. In a previous study, Shamsoddini and Hollisaz ${ }^{27}$ applied taping to patients with tennis elbow to significantly reduce post-intervention pain compared to pre-intervention, and Vicenzino et al. ${ }^{21}$ found that the diamond taping technique used other taping techniques. When applied, the post-intervention pressure pain threshold for post-intervention pain was significantly higher than pre-intervention, and was significantly higher 30 minutes after intervention. It was found that the results of this study were similar to the results of the previous study. It was found that applying taping to tennis elbow patients was a psychophysiological model. It is believed that it has been effective in reducing pain in tennis

Table 1. Outcome measure data at baseline for both groups

\begin{tabular}{ccccc}
\hline Variable & $\begin{array}{c}\text { Taping group } \\
(N=15)\end{array}$ & $\begin{array}{c}\text { Taping+DFM group } \\
(N=15)\end{array}$ & $t$ value \\
\hline VAS $^{\mathrm{a}}$ & $5.30 \pm 1.25^{\mathrm{c}}$ & $5.20 \pm 0.96$ & .246 & .269 \\
PRTEE $^{\mathrm{b}}$ & $33.43 \pm 8.04$ & $31.63 \pm 7.49$ & .635 & .997 \\
\hline Pain-free grip strength (N) & $26.16 \pm 10.70$ & $21.87 \pm 7.46$ & 1.273 & .096 \\
\hline Wrist extension strength (N) & $83.94 \pm 24.97^{\mathrm{b}}$ & $85.19 \pm 25.91$ & -.135 & .708 \\
\hline Wrist Extensor $\left(\% \mathrm{MVIC}^{\mathrm{d}}\right)$ & $61.25 \pm 6.98$ & $71.47 \pm 8.19$ & -3.678 & .754 \\
\hline
\end{tabular}

${ }^{\mathrm{a}}$ visual analogue scale; ${ }^{\mathrm{b}}$ patient-rated tennis elbow evaluation; ${ }^{\mathrm{c}}$ means \pm standard deviation; ${ }^{\mathrm{d}}$ maximum voluntary isomeric contraction.

Table 2. Changes in outcome measure variables between pre- and post-intervention

\begin{tabular}{|c|c|c|c|c|c|c|}
\hline & \multicolumn{2}{|c|}{ Time } & \multicolumn{2}{|c|}{ Group } & \multicolumn{2}{|c|}{ Time×Group } \\
\hline & $\mathrm{F}$ & $p$ & $\mathrm{~F}$ & $p$ & $\mathrm{~F}$ & $p$ \\
\hline VAS $^{\mathrm{a}}$ & 319.361 & $<.001^{*}$ & .114 & $.004^{*}$ & .777 & .386 \\
\hline PRTEE $^{\mathrm{b}}$ & 381.713 & $<.001^{*}$ & .029 & .867 & 4.981 & $.034^{*}$ \\
\hline Pain-free grip strength $(\mathrm{N})$ & 545.568 & $<.001^{*}$ & 25.593 & $<.001^{*}$ & 2.166 & .072 \\
\hline Wrist extension strength $(\mathrm{N})$ & 158.909 & $<.001^{*}$ & .146 & .706 & 22.454 & $<.001^{*}$ \\
\hline Wrist Extensor (\%MVIC ${ }^{\mathrm{d}}$ ) & 14.283 & $.001^{*}$ & 2.763 & .108 & 2.905 & .099 \\
\hline
\end{tabular}

${ }^{\mathrm{a}}$ visual analogue scale; ${ }^{\mathrm{b}}$ patient-rated tennis elbow evaluation; ${ }^{\mathrm{c}}$ means \pm standard deviation; ${ }^{\mathrm{d}}$ maximum voluntary isomeric contraction; ${ }^{*} p<.05$. 
Table 3. Results of within-group comparisons

\begin{tabular}{|c|c|c|c|}
\hline Variable & Pre-intervention & Post-intervention & $p$ value \\
\hline \multicolumn{4}{|l|}{$\mathrm{VAS}^{\mathrm{a}}$} \\
\hline Taping group & $5.2 \pm 0.96^{\mathrm{c}}$ & $1.67 \pm 0.50$ & $<.001^{*}$ \\
\hline Taping+DFM group & $5.3 \pm 1.25$ & $1.4 \pm 0.63$ & $<.001^{*}$ \\
\hline \multicolumn{4}{|l|}{ PRTEE $^{\mathrm{b}}$} \\
\hline Taping group & $31.63 \pm 7.50$ & $14.83 \pm 5.60$ & $<.001^{*}$ \\
\hline Taping+DFM group & $33.43 \pm 8.03$ & $12.30 \pm 4.17$ & $<.001^{*}$ \\
\hline \multicolumn{4}{|c|}{ Pain-free grip strength $(\mathrm{N})$} \\
\hline Taping group & $21.87 \pm 7.47$ & $24.50 \pm 7.70$ & $<.001^{*}$ \\
\hline Taping+DFM group & $26.16 \pm 10.70$ & $30.24 \pm 10.95$ & $<.001^{*}$ \\
\hline \multicolumn{4}{|c|}{ Wrist extension strength $(\mathrm{N})$} \\
\hline Taping group & $85.19 \pm 25.91$ & $93.33 \pm 26.80$ & $<.001^{*}$ \\
\hline Taping+DFM group & $83.94 \pm 24.97$ & $101.88 \pm 27.59$ & $<.001^{*}$ \\
\hline \multicolumn{4}{|c|}{ Wrist extensor (\%MVIC $\left.{ }^{\mathrm{d}}\right)$} \\
\hline Taping group & $71.47 \pm 8.19$ & $76.77 \pm 7.57$ & $.010^{*}$ \\
\hline Taping+DFM group & $61.25 \pm 6.98$ & $75.25 \pm 19.03$ & $.017^{*}$ \\
\hline
\end{tabular}

${ }^{\mathrm{a}}$ visual analogue scale; ${ }^{\mathrm{b}}$ patient-rated tennis elbow evaluation; ${ }^{\mathrm{c}}$ means \pm standard deviation; ${ }^{\mathrm{d}}$ maximum voluntary isomeric contraction; ${ }^{*} p<.05$.

elbow patients by substantiating research that alters pain perception. Also, Nagrale et al. ${ }^{20}$ have shown results of reducing pain when applying DFM and steroid injections to tennis elbow patients respectively, and Verhaar et al. ${ }^{12}$ applied Mill's manipulation with DFM to play tennis. It significantly reduced the pain in elbow patients. Also, Baltaci et al. ${ }^{28}$ showed that DFM and Mill's manipulation were applied, and the pain was significantly reduced as compared with the group to which general physical therapy was applied. Also, Olaussen et al. ${ }^{15}$ significantly reduced pain in a group of tennis elbow patients who received DFM, Mill's manipulation, and corticosteroid injection. The results of previous studies can support the results of this study that DFM increases pain thresholds associated with pain and skin conductance and blood flow rate to increase sympathetic nervous system response and reduce pain. It is believed that it can be used in an effective way to treat patients. Moreover, the results based on the application of a single treatment technique can be applied together with other treatments, but the study results that there is no other difference, this is a way to reduce pain, applying many methods. Even suggests the importance of using more effective treatment methods for patients.

In this study showed that the effect of mediation method for function of tennis elbow patients showed significantly improved results both pre and post intervention, and the effect of improved function between groups showed significant difference. In a previous study, Halim-Kertanegara et al. ${ }^{29}$ showed a significant increase in functional score and increased functional movement when taping was applied to patients with ankle instability. Lee et al. ${ }^{30}$ conducted a study that applied positive taping to stroke patients and found a positive effect on the motion of reaching for the paralyzed person. And Dimitrios and Ioannis ${ }^{31}$ applied DFM to improve the function of tennis elbow patients. Tools for assessing functional areas together measure pain and functional scores, suggesting that functional movements are often associated with pain. In this study, the result of applying taping and DFM to improve function is that two intervention methods reduce all pain and improve the functional movement resulting from the decrease in pain when it causes movement. Less pain is fed as improved function. Also, taping and DFM applied together had improved function over single-treatment groups, but no effective way to improve pain was determined. Applying multiple mediations is considered to be a synergistic effect of taping and DFM.

In this study, the muscle strength of tennis elbow patients showed significantly increased results pre and post intervention, both in the taped group and in the taped and DFM 
Table 4. Results of between-group comparison in the change value

\begin{tabular}{|c|c|c|c|}
\hline Variable & Taping+DFM group $\left(\mathrm{n}_{1}=15\right)$ & Taping group $\left(\mathrm{n}_{2}=15\right)$ & $p$ value \\
\hline $\mathrm{VAS}^{\mathrm{a}}$ & $1.40 \pm 0.63^{c}$ & $1.67 \pm 0.49$ & .207 \\
\hline PRTEE $^{b}$ & $12.30 \pm 4.17$ & $14.83 \pm 5.55$ & .169 \\
\hline Pain-free grip strength (N) & $30.24 \pm 10.95$ & $24.50 \pm 7.70$ & .107 \\
\hline Wrist extension strength $(\mathrm{N})$ & $101.88 \pm 27.59$ & $93.33 \pm 26.80$ & .397 \\
\hline Wrist Extensor (\%MVIC ${ }^{\mathrm{d}}$ ) & $75.25 \pm 19.03$ & $76.77 \pm 9.57$ & .785 \\
\hline
\end{tabular}

${ }^{\mathrm{a}}$ visual analogue scale; ${ }^{\mathrm{b}}$ patient-rated tennis elbow evaluation; ${ }^{\mathrm{c}}$ means \pm standard deviation; ${ }^{\mathrm{d}}$ maximum voluntary isomeric contraction; ${ }^{*} p<.05$.

combined group, and the differences between the groups also showed significant results. In a previous study, Shamsoddini and Hollisaz ${ }^{25}$ applied taping to tennis elbow patients and found that their pain-free grip strength was significantly increased and their wrist extension strength increased. Also, Vicenzino et al. ${ }^{21}$ applied taping to increase the pain-free grip strength. Applying taping, the results of increased muscle strength and the results of previous studies show that the body segment is anchored to create more tension and to increase muscle strength than the unfixed site. In addition, in a previous study, Nagrale et al. ${ }^{20}$ found that Pain-free grip strength was significantly increased by applying DFM to tennis elbow patients, and Molouki et al. ${ }^{32}$ applied manual therapy to Pain-free grip strength. There was a study that increased free grip strength and Hand grip endurance. It is considered that the reason why DFM increased the muscle strength was that it directly acts on the muscle, and the normal soft tissue fibrous muscle arrangement by this causes the muscle strength to increase.

Pain-free grip strength and wrist extension strength between groups in which DFM and taping were applied together and taping alone were significantly increased in this study before taping was applied in the group in which taping and DFM were applied together. After applying DFM and Mill's manipulation for 15 minutes, Diamond taping

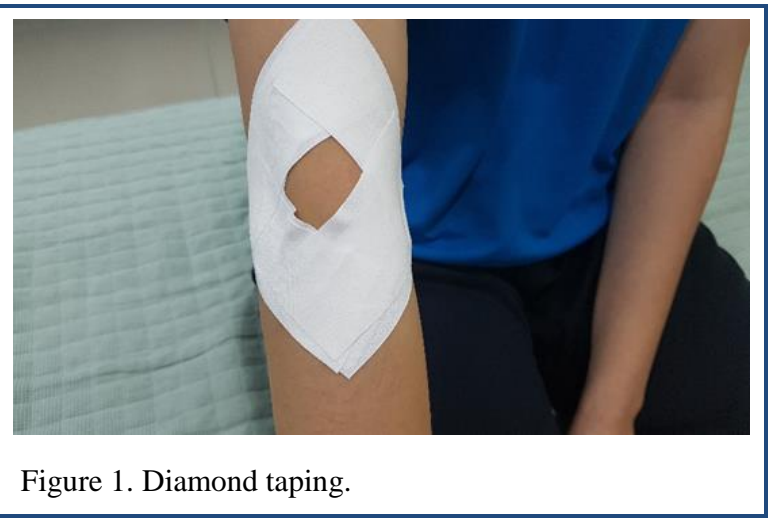

was applied, and the electromyogram after intervention increased from the results of this study. Muscle strength and EMG are groups in which DFM and taping are applied together while the effect of increased EMG in intervention of DFM known to be related is maintained by applying taping. ${ }^{32}$ It is considered that the strength and wrist extension strength increased significantly compared to the group where only taping was applied. ${ }^{21,23,25}$ Therefore, it is considered that applying DFM and then taping to tennis elbow patients is an effective way to increase the muscle strength of the patients.

In our study, wrist extensor EMG was significantly increased pre and post intervention, both in the taped group and in the taped and DFM co-administered group. However, there was no significant difference between the groups. In a previous study, Lee et al. ${ }^{33}$ found significant results comparing the muscle activity of Abductor hallucis with short foot exercise by applying taping to patients with patellofemoral pain syndrome. There was a study in which DFM was not applied to muscles and muscle activity was significantly increased. This means that taping and DFM had the effect of increasing the muscle activity of each muscle. Taping increases blood volume in the soft tissue under the skin to increase muscle activity, and DFM can directly stimulate muscles to increase muscle activity. The insignificant effect of taping and DFM between groups is due to the fact that the distance between skin and muscle increases after taping because the position to measure muscle activity and the position to attach taping are the same. It is probable that there was interference in the electrogram measurement. Therefore, promoting and increasing the muscle activity of tennis elbow patients is considered to be effective for both the therapeutic method of applying taping and the therapeutic method of applying taping and DFM together, and both are recommended in the therapeutic method of patients. It is thought that it can be done.

The limitation of this study is that only tennis elbow patients were measured. We were unable to measure the 
elbow strength and muscle activity that could be commonly displayed because we measured the pain and function, muscle strength, and muscle activity that could be displayed from tennis patients. In a future study, when measuring and comparing the muscle strength and muscle activity of subjects without tennis elbow and tennis elbow patients, we compared the difference in mediation effect between tennis elbow patients and target companies without symptoms, Research on intervention effects and preventive measures may be conducted.

Another limitation was not excluded posture and placement, as well as upper limb history and injury of tennis elbow patients. Muscle strength of the wrist and range of motion of the elbow and shoulder showed other grip strength depending on the position and angle of the head and elbow and shoulder, but there was a previous study. ${ }^{24}$ Therefore, this is an interesting study to compare the difference in muscle strength and electromyography of tennis elbow patients with different head and neck postures and shoulder positions.

\section{CONCLUSIONS}

In our study, we investigated how taping and DFM techniques affect pain, function, strength and activity in tennis elbow patients. The current findings showed a significant decrease in elbow pain and increased muscle activity after mediated both by taping plus DFM and taping alone group. After intervention, both function and strength were significantly increased among the groups. Taping and DFM may be used in effective treatment methods to treat tennis elbow patients, respectively, but when taping and DFM are applied together, they are used in a way to improve tennis elbow patient function and strength more effectively.

\section{Key Points}

Question Is it more effective to apply taping technique and manual therapy together to improve muscle strength, pain, function and wrist extensor muscle activity in tennis elbow patients than to apply taping technique alone to tennis elbow patients?

Findings In this randomized trial of 30 young adults, manual therapy and taping technique to reduce pain and inflammation and improve muscle activity were included in the intervention and were more manual than those applying the taping technique intervention. Pain, function, muscle strength, and muscle activity were significantly improved in response to the combined intervention of therapy and taping technique.
Meaning Manual therapy and taping technique interventions that reduce pain and inflammation and improve muscle activity can provide clinical benefits to improve pain, function, strength and activity in tennis elbow patients.

\section{Article information}

Conflict of Interest Disclosures: None.

Funding/Support: None.

Acknowledgment: None.

Ethic Approval: This study was conducted after passing the deliberation of the Institutional Bioethics Committee of Inje University (INJE2016-11-016-002).

\section{REFERENCES}

1. Labelle H, Guibert R, Joncas J, Newman N, Fallaha M, Rivard C. Lack of scientific evidence for the treatment of lateral epicondylitis of the elbow: an attempted metaanalysis. J Bone Joint Surg. 1992;74: 646-651.

2. Noteboom T, Cruver S, Keller A, Kellog F, Nitz A. Tennis elbow: a review. J Orthop Sports Phys Ther. 1994;19: 357-366.

3. Vicenzino B, Wright A. Lateral epicondylalgia I: epidemiology, pathophysiology, aetiology and natural history. Phys Ther Rev. 1996;1:23-34.

4. Haker E. Lateral epicondylalgia: diagnosis, treatment and evaluation. Crit Rev Phys Rehabil Med. 1993;5:129-154.

5. Trudel D, Duley J, Zastrow I, Kerr E, Davidson R, MacDermid J. Rehabilitations for patients with lateral epicondylitis: a systematic review. J Hand Ther. 2004;17: 243-66.

6. Bot SD, van der Waal JM, Terwee CB, et al. Incidence and prevalence of complaints of the neck and upper extremity in general practice. Ann Rheum Dis. 2005; 64(1):118-127.

7. Chard MD, Hazleman BL. Tennis elbow-a reappraisal. Br J Rheumatol. 1989;28(3):186-190.

8. Murtagh J. Tennis elbow. Aust Fam Physician. 1984; 13(1):51.

9. Kraushaar BS, Nirschl RP. Tendinosis of the elbow (tennis elbow). Clinical features and findings of histological, immunohistochemical, and electron microscopy studies. J Bone Joint Surg Am. 1999;81(2):259-278.

10. Scott A, Docking S, Vicenzino B, et al. Sports and exercise-related tendinopathies: a review of selected topical issues by participants of the second International Scientific Tendinopathy Symposium (ISTS) Vancouver 2012. Br J Sports Med. 2013;47(9):536-544.

11. Hayton MJ, Santini AJ, Hughes PJ, Frostick SP, Trail IA, 
Stanley JK. Botulinum toxin injection in the treatment of tennis elbow. A double-blind, randomized, controlled, pilot study. J Bone Joint Surg Am. 2005;87(3):503-507.

12. Verhaar JA, Walenkamp GH, van Mameren H, Kester $\mathrm{AD}$, van der Linden AJ. Local corticosteroid injection versus Cyriax-type physiotherapy for tennis elbow. $J$ Bone Joint Surg Br. 1996;78(1):128-132.

13. Bisset L, Beller E, Jull G, Brooks P, Darnell R, Vicenzino B. Mobilisation with movement and exercise, corticosteroid injection, or wait and see for tennis elbow: randomised trial. BMJ. 2006;333:939.

14. Coombes BK, Bisset L, Vicenzino B. Efficacy and safety of corticosteroid injections and other injections for management of tendinopathy: a systematic review of randomised controlled trials. Lancet. 2010;376(9754): 1751-1767.

15. Olaussen M, Holmedal O, Lindbaek M, Brage S, Solvang H. Treating lateral epicondylitis with corticosteroid injections or non-electrotherapeutical physiotherapy: a systematic review. BMJ Open. 2013;3(10): e003564.

16. Coombes BK, Bisset L, Brooks P, Khan A, Vicenzino B. Effect of corticosteroid injection, physiotherapy, or both on clinical outcomes in patients with unilateral lateral epicondylalgia: a randomized controlled trial. JAMA. 2013;309(5):461-469.

17. McConnell J, McIntosh B. The effect of tape on glenohumeral rotation range of motion in elite junior tennis players. Clin J Sport Med. 2009;19(2):90-94.

18. Cyriax J. Diagnosis of soft tissue lesions. In: Cyriax J editor (s). Textbook of orthopaedic medicine. 9th Edition. Vol. 1. Baltimore: Williams and Wilkins; 1975.

19. Cyriax J. Treatment by manipulation, massage and injection. In: Cyriax J editor(s). Textbook of orthopaedic medicine. 9th Edition. Vol.2, Baltimore: Williams and Wilkins, 1975.

20. Nagrale AV, Herd CR, Ganvir S, Ramteke G. Cyriax physiotherapy versus phonophoresis with supervised exercise in subjects with lateral epicondylalgia: a randomized clinical trial. J Man Manip Ther. 2009;17(3): 171-178.

21. Vicenzino B, Brooksbank J, Minto J, Offord S, Paungmali A. Initial effects of elbow taping on pain-free grip strength and pressure pain threshold. J Orthop Sports Phys Ther. 2003;33(7):400-407.

22. Bohannon RW, Bear-Lehman J, Desrosiers J, MassyWestropp N, Mathiowetz V. Average grip strength: a meta-analysis of data obtained with a Jamar dynamometer from individuals 75 years or more of age. $J$ Geriatr Phys Ther. 2007;30(1):28-30.

23. Chang HY, Chou KY, Lin JJ, Lin CF, Wang CH. Immediate effect of forearm Kinesio taping on maximal grip strength and force sense in healthy collegiate athletes. Phys Ther Sport. 2010 ;11(4):122-127.

24. Kong YK. The effect of co-ordinating postures with shoulder and elbow flexion angles on maximum grip strength and upper-limb muscle activity in standing and sitting postures. Int J Occup Saf Ergon. 2014;20(4):595606.

25. Shamsoddini A, Hollisaz MT, Hafezi R. Initial effect of taping technique on wrist extension and grip strength and pain of individuals with lateral epicondylitis. Iran Rehab J. 2010;8(11):24-28.

26. Lee DR, Kim JS. Reliability and validity of the Korean version of patient-rated tennis elbow evaluation. KSPM. 2014;9(1):25-33.

27. Shamsoddini A, and Hollisaz MT. Effects of taping on pain, grip strength and wrist extension force in patients with tennis elbow. Trauma Mon. 2013;18(2): 71-74.

28. Baltaci G, Ergun N, Bayrakci Tunay V. Effectiveness of Cyriax manipulative therapy and elbow band in the treatment of lateral epicondylitis. J Sports Traumatol Rel Res. 2001;23:113-118.

29. Halim-Kertanegara S, Raymond J, Hiller CE, Kilbreath SL, Refshauge KM. The effect of ankle taping on functional performance in participants with functional ankle instability. Phys Ther Sport. 2017; 23: 162-167.

30. Lee DH, Kim WJ, Oh JS, Chang M. Taping of the elbow extensor muscle in chronic stroke patients: comparison between before and after three-dimensional motion analysis. J Phys Ther Sci. 2015; 27(7):2101-2103.

31. Stasinopoulos D, Stasinopoulos I. Comparison of effects of Cyriax physiotherapy, a supervised exercise programme and polarized polychromatic non-coherent light (Bioptron light) for the treatment of lateral epicondylitis. Clin Rehabil. 2006;20(1):12-23.

32. Molouki A, Hosseini SM, Rustaee M, Tabatabaee SM. The immediate effects of manual massage of forearm on power-grip strength and endurance in healthy young men. J Chiropr Med. 2016;15(2):112-120.

33. Lee J, Yoon J, Cynn H. Foot exercise and taping in patients with patellofemoral pain and pronated foot. $J$ Bodyw Mov Ther. 2017;21(1):216-222. 